\title{
PEMBELAJARAN MATEMATIKA BERBANTUAN MAPLE \\ PADA MATA KULIAH KALKULUS INTEGRAL TERHADAP KEMAMPUAN KOMUNIKASI MATEMATIS MAHASISWA
}

\author{
${ }^{1}$ Retni Paradesa, ${ }^{2}$ Yunika Lestaria Ningsih \\ ${ }^{1,2}$ Dosen Universitas PGRI Palembang \\ 11retni.paradesa@yahoo.com, ${ }^{2}$ yunika@univpgri-palembang.ac.id
}

\begin{abstract}
This study aims to determine the effect of learning mathematics assisted Maple on Integral Calculus valid course for student learning on the mathematical communication ability of prospective teachers. The design of this research is non equivalent control group design. The experimental class was provided with Maple-assisted learning treatment and control class given direct learning. The research data used is the instrument with the test problem of mathematical communication ability. Population in this research is all student of teacher candidate of second semester of Mathematics Education in one PTS with sample chosen by second semester student which taken two class based on saturated sample. This research is experimental research of Quasi Experimental type which aims to know mathematical communication ability of student of teacher candidate at integral calculus course that fulfill effective criteria. Data from process skill variable is taken with observation, while data from mathematical communication ability variable is taken with test. Data were analyzed quantitatively, posttest data of mathematical communication ability of prospective teacher students. The results show that, (1) there is an effect of mathematical communication ability of prospective teachers who get the help of Maple supported better than the students who get the direct learning. (2) The quality of mathematical communication ability in the group of students who received Maple assisted learning included into the high category, while the group of students who received the direct learning included into the medium category.
\end{abstract}

Keywords: Maple Assisted Learning, Mathematical Communication Skills

\begin{abstract}
ABSTRAK
Penelitian ini bertujuan untuk mengetahui pengaruh pembelajaran matematika berbantuan Maple pada matakuliah Kalkulus Integral yang valid untuk belajar mahasiswa terhadap kemampuan komunikasi matematis mahasiswa calon guru. Desain penelitian ini adalah non equivalent control group design. Kelas eksperimen diberikan perlakuan pembelajaran berbantuan Maple dan kelas kontrol diberikan pembelajaran langsung. Data penelitian yang digunakan adalah instrumen dengan soal tes kemampuan komunikasi matematis. Populasi dalam penelitian ini adalah seluruh mahasiswa calon guru semester II Pendidikan Matematika di salah satu PTS dengan sampel dipilih mahasiswa semester II yang diambil dua kelas berdasarkan sampel jenuh. Penelitian ini merupakan penelitian eksperimen jenis Quasi Experimental yang bertujuan untuk mengetahui kemampuan komunikasi matematis mahasiswa calon guru pada matakuliah kalkulus integral yang memenuhi kriteria efektif. Data dari variabel keterampilan proses diambil dengan pengamatan, sedangkan data dari variabel kemampuan komunikasi
\end{abstract}


matematis diambil dengan tes. Data dianalisis kuantitatif, posttest data kemampuan komunikasi matematis mahasiswa calon guru. Hasil memperlihatkan bahwa, (1) ada pengaruh kemampuan komunikasi matematis mahasiswa calon guru yang memperoleh pembelajaran berbantuan Maple lebih baik daripada mahasiswa yang memperoleh pembelajaran langsung. (2) Kualitas kemampuan komunikasi matematis pada kelompok mahasiswa yang mempeoleh pembelajaran berbantuan Maple termasuk kedalam kategori tinggi, sedangkan kelompok siswa yang memperoleh pembelajaran langsung termasuk ke dalam kategori sedang.

Kata Kunci : Pembelajaran Berbantuan Maple, Kemampuan Komunikasi Matematis

\section{PENDAHULUAN}

Tujuan pembelajaran matematika telah dirumuskan oleh National Council of Teachers of Mathematics (2000) yaitu agar peserta didik memiliki kompetensi : (1) memecahkan masalah (mathematical problem solving); (2) bernalar (mathematical reasoning); (3) berkomunikasi (mathematical communication); (4) mengaitkan ide (mathematical connection); (5) bersikap positif terhadap matematika (positive attitudes toward mathematics). Selain itu Peraturan Menteri Pendidikan Nasional No. 20 Tahun 2006 menegaskan bahwa tujuan pembelajaran matematika pada jenjang pendidikan dasar dan menengah adalah agar peserta didik mampu untuk: (1) memiliki pengetahuan matematika (konsep, keterkaitan antarkonsep, dan algoritma), (2) menggunakan penalaran, (3) memecahkan masalah, (4) mengomunikasikan gagasan dengan simbol, tabel, diagram, atau media lain untuk memperjelas keadaan atau masalah dan (5) memiliki sikap menghargai kegunaan matematika.

Di dalam kegiatan pembelajaran matematika, kemampuan komunikasi matematis sangat diperlukan, karena dua alasan penting seperti yang dikemukakan oleh (Baroody, 1993), yaitu yaitu: (1) mathematics is essentially a language; dan (2) mathematics and mathematics learning are, at heart, social activities;dari pendapat tersebutdapat dikatakan bahwa matematika merupakan alat bantu berpikir, alat menemukan pola, menyelesaikan masalah, atau membuat kesimpulan, sehingga matematika merupakan alat yang tak terhingga nilainya untuk mengkomunikasikan berbagai ide dengan jelas, tepat, dan ringkas. Selain itu juga, matematika dapat dianggap sebagai aktivitas sosial dalam pembelajaran matematika, interaksi antar peserta didik, seperti komunikasi antara guru dan siswa yang menjadi bagian penting untuk mengembangkan potensi matematika siswa. 
Di dalam kegiatan pembelajaran matematika, Sumarna (Syaban, 2008) menyatakan bahwa komunikasi matematis meliputi beberapa kemampuan peserta didik, antara lain : (1) menghubungkan benda nyata, gambar, diagram ke dalam ide matematika : (2) menjelaskan ide, situasi, dan relasi matematika secara lisan atau tulisan dengan benda nyata, gambar, grafik, dan aljabar; (3) menyatakan peristiwa sehari-hari dalam bahasa atau simbol matematika; (4) mendengarkan, berdiskusi, dan menulis tentang matematika; (5) membaca dengan pemahaman atau presentasi matematika tertulis; (6) menyusun argumen, menuliskan defisini dan generalisasi; dan (7) menjelaskan dan membuat pertanyaan tentang matematika yang telah dipelajari. Dari pendapat tersebut dapat disimpulkan bahwa komunikasi matematis dapat disampaikan melalui lisan maupun tulisan. Artinya peserta didik mengalami proses belajar melalui kegiatan mendengarkan, berargumentasi, membaca, dan menulis gagasan. Siswa dapat menuangkan ide matematika dengan berbicara, menulis, menggambar, membuat gambar dan grafik, serta berdemontrasi dengan model, atau alat peraga.

Komunikasi matematis merupakan esensi dari belajar dan mengakses matematika (Lindquist dan Elliot, 1996). Selanjutnya Polla (1999) menyatakan bahwa komunikasi menjadi hal utama dalam pembelajaran matematika. Selain itu, Lim dan Pugalee (2005) menyatakan pula bahwa komunikasi (bahasa) merupakan komponen penting di dalam pemahaman konsep matematika. Dari beberapa pendapat tersebut maka dapat disimpulkan bahwa kemampuan komunikasi matematis perlu dikuasai oleh peserta didik, dan pendidik perlu menghadirkan suatu pembelajaran yang dapat melatih dan mengembangkan kemampuan komunikasi matematis tersebut.

Kemampuan komunikasi matematis merupakan salah satu kemampuan matematis yang mendukung kemampuan siswa dalam menguasai konsep matematika secara umum. Hal ini sesuai dengan pendapat Stacey (2005) yang menyatakan bahwa kemampuan komunikasi matematis merupakan salah satu faktor yang memberikan kontribusi dan turut menentukan keberhasilan di dalam menyelesaikan masalah. Artinya kemampuan komunikasi matematis merupakan salah satu syarat untuk dapat memecahkan masalah matematis. Dari pernyataan tersebut maka dapat dikatakan bahwa untuk dapat menyelesaikan permasalahan matematis maka diperlukan penguasaan kemampuan komunikasi matematis yang baik juga. 
Mengingat pentingnya kecakapan komunikasi matematis maka salah satu tugas pendidik adalah memilih metode, pendekatan, atau model pembelajaran yang sesuai dan dapat digunakan di dalam kegiatan pembalajaran sehingga dapat mengembangkan kemampuan komunikasi matematis. Salah satu pendekatan pembelajaran yang dapat digunakan adalah pembelajaran matematika berbantuan Maple.

Namun kenyataannya untuk mewujudkan hal tersebut tidak lah mudah. Dunia pendidikan saat ini telah banyak sekali mengalami perubahan baik dari segi muatan kurikulum sampai dengan penggunaan media yang digunakan dalam proses pembelajaran. Media yang digunakan tidak hanya papan dan alat tulis saja, tetapi juga media yang relatif lebih baru, yang diharapkan dapat menunjang proses pembelajaran. Salah satu alternatif media yang dapat diintegrasikan dalam proses pembelajaran adalah media yang berbasis teknologi ( Sadiman, 2005). Ini berarti, setiap tenaga pengajar harus mampu berinovasi dalam proses pembelajaran, sehingga pembelajaran yang dihasilkan sesuai dengan perkembangan dunia pendidikan.

Salah satu produk dari ilmu pengetahuan dan teknologi yang sedang populer saat ini adalah perangkat komputer dan program aplikasinya. Komputer merupakan suatu piranti yang dapat melakukan operasi hitung atau mengolah data dan menyajikan hasilnya sebagai informasi (Ibrahim, 2009:109). Menurut Kartono, 2005 komputer yang merupakan suatu sistem yang terdiri atas perangkat software dan hardware mengalami pertumbuhan yang pesat, bahkan komputer disebut-sebut sebagai tonggak awal revolusi teknologi digital. Menurut Gordon Dryden \& Jeannatte Vos (Hardianto, 2012:2) revolusi teknologi komputer yang semakin canggih dengan ukuran semakin kecil namun memiliki kapasitas dan kecepatan yang semakin besar, fungsinya semakin meluas seiring dengan berkembangnya temuan-temuan kreatif perangkat lunaknya (software) akan menyebabkan terjadinya revolusi dalam belajar. Komputer yang semula sekadar untuk membantu memecahkan hitung-hitungan rumit kini bisa dipakai untuk olah kata, olah data, olah gambar, dan pangkalan data berbagai bidang kehidupan.

Paradesa, Zulkardi dan Darmawijoyo (2010) telah melakukan inovasi pembelajaran dengan mengembangkan pembelajaran melalui Macromedia Flash dan Maple dan menghasilkan bahan ajar kalkulus II, begitu juga Afgani (2016) yang telah mengembangkan bahan ajar.

Pada latar belakang standar isi mata pelajaran matematika untuk SMA/MA tertulis "Untuk meningkatkan keefektifan pembelajaran, sekolah diharapkan menggunakan 
teknologi informasi dan komunikasi seperti komputer, alat peraga atau media lainnya. Selain itu, perlu ada pembahasan mengenai bagaimana matematika banyak diterapkan dalam teknologi informasi sebagai perluasan pengetahuan peserta didik". Dari kalimat tersebut dapat diambil simpulan bahwa guru diharapkan mau menggunakan/memanfaatkan media untuk dapat/lebih meningkatkan keefektifan pembelajaran-nya.

Materi pada pelajaran matematika adalah materi yang banyak menyajikan tabel, gambar, diagram, dan grafik. Dalam hal ini, yang perlu dilakukan mahasiswa dalam materi yang memuat aspek-aspek tersebut adalah bagaimana mahasiswa dapat memahami dan menyajikan data serta mengkomunikasikan informasi yang diperoleh sehingga data-data dari hasil perhitungan menjadi lebih bermakna.

Sehubungan dengan hal tersebut, maka pengajar selaku fasilitator dan mediator dalam pengajaran dan pembelajaran, harus melakukan inovasi yang memberikan wawasan dan pengalaman baru bagi mahasiswa dalam belajar serta dapat meningkatkan kemampuankemampuan matematis, khususnya kemampuan komunikasi matematis siswa.

\section{METODE PENELITIAN}

Penelitian ini merupakan penelitian Quasi-Experimental karena subjek tidak dikelompokkan secara acak, tetapi diterima apa adanya. Pada penelitian ini, peneliti memberikan perlakuan kepada subjek penelitian untuk selanjutnya ingin diketahui pengaruh perlakuan tersebut. Perlakuan tersebut adalah pembelajaran Kalkulus Integral berbasis Maple (PBM) yang diterapkan pada kelas eksperimen. Desain penelitian yang digunakan adalah desain kelompok kontrol postes non-ekivalen atau Nonequivalent Post-Test Control-Group Design. Subjek penelitian ini adalah mahasiswa semester genap tahun akademik 2016/2017 di Program Studi Pendidikan Matematika Fakultas Keguruan dan Ilmu Pendidikan tingkat strata 1, pada salah satu perguruan tinggi swasta (PTS) kota Palembang. Subjek penelitian berjumlah 61 orang mahasiswa yang terdiri dari 2 kelas paralel, kelas eksperimen (31 orang), sedangkan kelas lainnya sebagai kelas kontrol (30 orang). Sebelum dilakukan penelitian kedua kelas ini terlebih dahulu diuji kesetaraannya melalui tes Pengetahuan Awal Matematika (PAM). Pemilihan kelas eksperimen dan kelas kontrol dilakukan secara acak. Instrumen tes PAM dan tes kemampuan komunikasi matematis yang digunakan sudah diuji validitas, reliabilitas, daya pembeda dan tingkat kesukarannya. Soal tes dinyatakan telah memenuhi karakteristik yang memadai untuk digunakan dalam penelitian. 


\section{HASIL DAN PEMBAHASAN}

Penelitian ini dilaksanakan dari bulan Februari sampai bulan Mei 2017, dengan rincian yaitu dua kali pertemuan tes (PAM dan postes), dan empat kali pertemuan pembelajaran.

Hasil dari penelitian pada taraf signifikansi 5\% dirangkum dalam Tabel 1 sebagai berikut.

Tabel 1. Rangkuman Hasil Penelitian

\begin{tabular}{|c|c|c|c|c|c|c|}
\hline No & Data & Uji Normalitas & Uji homogenitas & Jenis Uji Statistik & Hipotesis Penelitian & Simpulan \\
\hline 1 & $\begin{array}{l}\text { Skor } \\
\text { PAM } \\
\text { kelas } \\
\text { eksperim } \\
\text { en dan } \\
\text { kelas } \\
\text { kontrol }\end{array}$ & $\begin{array}{l}\text { PAM kedua kelas } \\
\text { normal (Sig.= } \\
0,492 \\
<\alpha \text { ) } \\
\text { (Uji Kolmogorov- } \\
\text { Smirnov) } \\
\text { sedangkan kelas } \\
\text { kontrol normal } \\
\text { (Sig.= 0,682 } \\
>\alpha \text { ) } \\
\text { (Uji Kolmogorov- } \\
\text { Smirnov) }\end{array}$ & $\begin{array}{l}\text { Homogen (Sig.= } \\
0,521 \\
>\alpha) \\
\text { (Uji Levene) }\end{array}$ & $\begin{array}{l}\text { Uji Mann- } \\
\text { Witney(Sig.= } \\
0,795 \\
>\alpha)\end{array}$ & $\begin{array}{l}\text { Tidak terdapat } \\
\text { perbedaan } \\
\text { kemampuan awal } \\
\text { komunikasi } \\
\text { matematis kelas } \\
\text { eksperimen dan } \\
\text { kelas kontrol }\end{array}$ & $\begin{array}{l}\text { Hipotesis } \\
\text { diterima }\end{array}$ \\
\hline 2 & $\begin{array}{l}\text { Skor } \\
\text { postes } \\
\text { kelas } \\
\text { eksperim } \\
\text { en dan } \\
\text { kelas } \\
\text { kontrol }\end{array}$ & $\begin{array}{l}\text { Postes kelas } \\
\text { eksperimen } \\
\text { normal (Sig.= } \\
0.762 \\
<\alpha \text { ) sedangkan } \\
\text { kelas kontrol } \\
\text { normal (Sig.= } \\
0,198 \\
>\alpha \text { ) } \\
\text { (Uji Kolmogorov- } \\
\text { Smirnov) }\end{array}$ & $\begin{array}{l}\text { Homogen } \\
(\text { Sig.= 0,559 } \\
>\alpha) \\
\text { (Uji Levene) }\end{array}$ & $\begin{array}{l}\text { Uji Mann Witney } \\
\text { (Sig. }=0,000 \\
<\alpha)\end{array}$ & $\begin{array}{l}\text { Terdapat perbedaan } \\
\text { kemampuan } \\
\text { komunikasi } \\
\text { matematis setelah } \\
\text { pembelajaran pada } \\
\text { kelas eksperimen } \\
\text { dan kelas kontrol }\end{array}$ & $\begin{array}{l}\text { Hipotesis } \\
\text { diterima }\end{array}$ \\
\hline 3 & $\begin{array}{l}\text { Skor n- } \\
\text { gain } \\
\text { kemamp } \\
\text { uan } \\
\text { komunik } \\
\text { asi } \\
\text { matemati } \\
\text { s }\end{array}$ & $\begin{array}{l}\text { N-gain kelas } \\
\text { eksperimen } \\
\text { (Sig.=0,68) } \\
\text { maupun kelas } \\
\text { kontrol } \\
\text { (Sig.=0,47) normal } \\
\text { (Uji Kolmogorov- } \\
\text { Smirnov) }\end{array}$ & $\begin{array}{l}\text { Homogen } \\
\text { (Sig.=0,358) } \\
\text { (Uji Levene) }\end{array}$ & Uji-t & $\begin{array}{l}\text { Peningkatan } \\
\text { kemampuan } \\
\text { komunikasi } \\
\text { matematis } \\
\text { mahasiswa yang } \\
\text { mendapatkan } \\
\text { pembelajaran } \\
\text { berbantuan Maple } \\
\text { lebih baik } \\
\text { daripada mahasiswa } \\
\text { yang mendapatkan } \\
\text { pembelajaran } \\
\text { langsung }\end{array}$ & $\begin{array}{l}\text { Hipotesis } \\
\text { diterima }\end{array}$ \\
\hline
\end{tabular}

\section{Deskripsi Data PAM}

Tes PAM digunakan untuk mengetahui kesetaraan subjek sampel penelitian.

Rangkuman hasil analisis deskriptif data PAM berdasarkan pembelajaran disajikan pada 
Tabel 2. Selanjutnya dilakukan uji asumsi, yaitu uji normalitas dan uji homogenitas varians data PAM yang hasilnya dapat dilihat pada Tabel 3 dan Tabel 4.

TABEL 2. STATISTIK DESKRIPTIF DATA PAM

\begin{tabular}{|c|c|c|c|c|c|}
\hline \multirow{2}{*}{ Pembelajaran } & \multirow{2}{*}{$\mathbf{N}$} & \multicolumn{2}{|c|}{ Skor } & \multirow{2}{*}{ Rerata } & $\begin{array}{c}\text { Simpangan } \\
\text { Baku }\end{array}$ \\
\cline { 3 - 5 } & & Min & Maks & & 3,52 \\
\hline PBM & 31 & 4 & 16 & 8,90 & 3,52 \\
\hline Konvensional & 30 & 4 & 16 & 9,13 & 3,34 \\
\hline
\end{tabular}

Skor maksimal ideal : 20

TABEL 3. UJI NORMALITAS DATA PAM

\begin{tabular}{|c|c|c|c|c|}
\hline Pembelajaran & N & K-S & Sig. & Kesimpulan \\
\hline PBM & 31 & 0,832 & 0,492 & Normal \\
\hline Konvensional & 30 & 0,717 & 0,682 & Normal \\
\hline
\end{tabular}

TABEL 4. UJI HOMOGENITAS DATA PAM

\begin{tabular}{|c|c|c|c|c|}
\hline Pembelajaran & $\mathbf{N}$ & $\begin{array}{c}\text { Statistik } \\
\text { Lavene }\end{array}$ & Sig. & Kesimpulan \\
\hline PBM & 31 & 0,416 & 0,521 & Homogen \\
\hline Konvesional & 30 & &
\end{tabular}

Dari Error! Reference source not found.3 dapat dilihat nilai probabilitas (sig.) data PAM kelas PBM dan konvensional lebih besar dari taraf signifikasi 0,05, sehingga $\mathrm{H}_{0}$ diterima. Ini berarti data tersebut berdistribusi normal. Untuk uji homogenitas pada Tabel 4 diketahui bahwa data PAM juga lebih besar dari taraf signifikansi 0,05 ini juga berarti bahwa varians data homogen. Dengan demikian karena data berdistribusi normal dan homogen maka untuk mengetahui kesetaraan rerata dua kelas tersebut digunakan statistik parametrik yaitu uji t. Ringkasan hasil uji t dapat dilihat pada Tabel 5.

TABEL 5. UJI PERBEDAAN RERATA DATA PAM

\begin{tabular}{|l|l|l|}
\hline Kelas & Sig. & Kesimpulan \\
\cline { 1 - 2 } PBM & 0,795 & $\begin{array}{l}\text { Tidak ada } \\
\text { perbedaan }\end{array}$ \\
\hline Pembelajaran langsung
\end{tabular}

Tabel 5 menunjukkan bahwa nilai sig. lebih besar dari taraf signifikasi 0,05, sehingga $\mathrm{H}_{0}$ diterima. Artinya, tidak terdapat perbedaan yang signifikan pada rerata data PAM kelas sampel penelitian. Hasil ini memberikan kesimpulan bahwa mahasiswa pada kedua kelas sampel memiliki PAM yang setara. 
Deskripsi Data Peningkatan Kemampuan Komunikasi Matematis Mahasiswa

Statistik deskriptif data peningkatan kemampuan komunikasi matematis mahasiswa dapat dilihat pada Tabel 6. Sedangkan grafik PAM, postes dan peningkatan hasil belajar mahasiswa dapat dilihat pada Gambar 1. Pada Tabel 6 terlihat bahwa rata-rata postes keseluruhan mahasiswa yang mendapatkan PBM sebesar 10.90 sedangkan mahasiswa yang mendapatkan pembelajaran langsung sebesar 12,90. Rata-rata peningkatan hasil belajar mahasiswa pada PBM adalah sebesar 0,41 dan termasuk dalam kategori sedang, dan rerata peningkatan hasil belajar mahasiswa pada pembelajaran langsung adalah 0,47 juga termasuk dalam kategori sedang

TABEL 6. STATISTIK DESKRIPTIF DATA KEMAMPUAN KOMUNIKASI MATEMATIS MAHASISWA

\begin{tabular}{|l|l|l|l|l|l|l|l|l|l|}
\hline \multicolumn{9}{|c|}{ PBM } & \multicolumn{6}{l|}{$\begin{array}{l}\text { PEMBELAJARAN } \\
\text { LANGSUNG }\end{array}$} \\
\hline $\boldsymbol{N}$ & Stat. & PAM & Postes & $<$ g> & $\boldsymbol{n}$ & Stat. & PAM & Postes & $<$ g> \\
\hline \multirow{2}{*}{31} & $\bar{x}$ & 1.94 & 10.90 & 0.41 & \multirow{2}{*}{30} & $\bar{x}$ & 3,17 & 12,90 & 0,47 \\
\cline { 2 - 9 } & \multirow{2}{*}{$s$} & 0,81 & 1.81 & 0,08 & & $S$ & 0,83 & 3,04 & 0,14 \\
\hline
\end{tabular}

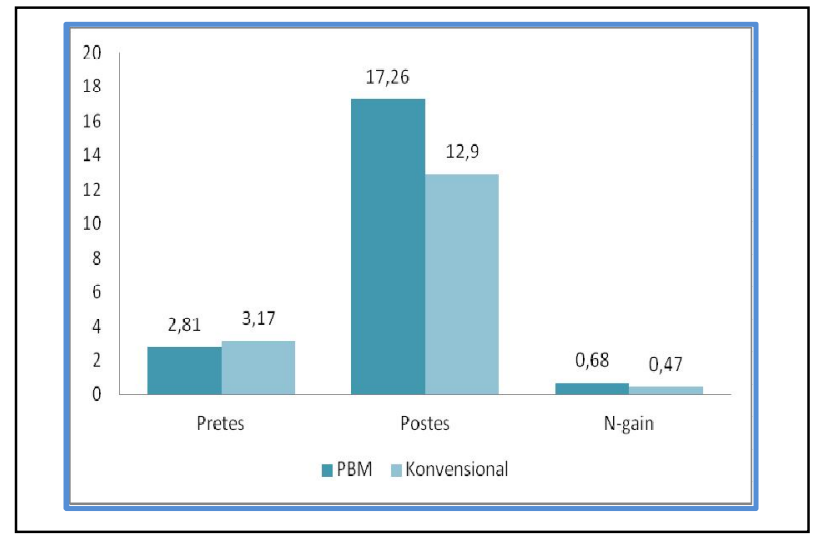

Gambar 1. Grafik Pretes, Postes dan N-gain

Untuk mengetahui apakah peningkatan kemampuan komunikasi matematis mahasiswa yang mendapat PBM lebih baik daripada mahasiswa yang mendapat pembelajaran konvensional, diajukan hipotesis sebagai berikut: mahasiswa yang mendapat PBM memperoleh peningkatan kemampuan komunikasi matematis lebih baik daripada mahasiswa yang mendapat pembelajaran konvensonal. Pengujian hipotesis tersebut diawali dengan melakukan uji prasyarat terlebih dahulu yaitu uji 
normalitas dan homogenitas data peningkatan kemampuan komunikasi matematis mahasiswa. Hasil uji normalitas dan homogenitas dapat dilihat pada Tabel 7 dan Tabel 8.

TABEL 7. UJI NORMALITAS DATA PENINGKATAN KEMAMPUAN KOMUNIKASI MATEMATIS MAHASISWA

\begin{tabular}{|l|l|l|l|l|}
\hline Pembelajaran & N & K-S & Sig. & Kesimpulan \\
\hline PBM & 31 & 0,666 & 0,767 & Normal \\
\hline $\begin{array}{l}\text { Pembelajaran } \\
\text { Langsung }\end{array}$ & 30 & 1,075 & 0,198 & Normal \\
\hline
\end{tabular}

TABEL 8. UJI HOMOGENITAS DATA PENINGKATAN KEMAMPUAN KOMUNIKASI MATEMATIS MAHASISWA

\begin{tabular}{|c|c|c|c|c|}
\hline Pembelajaran & $\mathbf{N}$ & $\begin{array}{l}\text { Statistik } \\
\text { Lavene }\end{array}$ & Sig. & Kesimpulan \\
\hline PBM & 31 & & & \\
\hline $\begin{array}{l}\text { Pembelajaran } \\
\text { langsung }\end{array}$ & 30 & 0,346 & 0,559 & Homogen \\
\hline
\end{tabular}

Berdasarkan Tabel 7 dan Tabel 8 diketahui bahwa data peningkatan hasil belajar mahasiswa berdistribusi normal dan homogen, oleh karena itu pengujian hipotesis dilanjutkan dengan uji $t$. Hasil uji $t$ dapat dilihat pada Tabel 9.

TABEL 9. UJI PERBEDAAN RERATA DATA PENINGKATAN KEMAMPUAN KOMUNIKASI MATEMATIS MAHASISWA

\begin{tabular}{|l|l|l|l|}
\hline Pembelajaran & $\boldsymbol{T}$ & Sig. & Kesimpulan \\
\hline PBM & 6,203 & 0,000 & $\begin{array}{l}\text { Ada } \\
\text { perbedaan }\end{array}$ \\
\hline $\begin{array}{l}\text { Pembelajaran } \\
\text { langsung }\end{array}$ & 6,200 & \\
\hline
\end{tabular}

Tabel 9 menunjukkan bahwa terdapat perbedaan rerata peningkatan kemampuan komunikasi matematis antara kelas PBM dengan Pembelajaran langsung. Hal ini berarti bahwa PBM secara signifikan lebih baik dalam meningkatkan kemampuan komunikasi matematis mahasiswa.

Dari hasil perhitungan persentase untuk setiap indikator, maka diketahui bahwa indikator kemampuan membaca dengan deskriptor mahasiswa membaca materi yang dijelaskan dengan memperhatikan simbol, rumus, tabel atau grafik yang tersedia pada bahan ajar memiliki memiliki rata-rata persentase tertinggi yaitu 97,44. Hal ini menunjukkan 
kemampuan mahasiswa membaca materi pelajaran sangat tinggi dengan kategori kemampuan komunikasi matematika dikategorikan sangat baik.

Sedangkan indikator kemampuan berbicara dengan deskriptor mahasiswa memberikan argumentasi dalam mempertahankan pendapat dengan memberikan bukti berupa fakta dan data yang jelas pada saat pembelajaran memiliki memiliki rata-rata persentase terendah 49,57. Hal ini menunjukkan bahwa kemampuan mahasiswa untuk memberikan argumentasi secara lisan menujukkan kemampuan komunikasi matematis mahasiswa masih dalam kategori kurang.

Untuk masing-masing indikator yang digunakan untuk mengukur kemampuan komunikasi matematis, diperoleh rata-rata terendah adalah indikator Kemampuan Berbicara dengan rata-rata persentasenya adalah 62,11. Artinya kemampuan komunikasi matematis mahasiswa dengan indkator kemampuan berbicara memiliki kategori cukup. Sedangkan indikator yang memiliki nilai rata-rata tertinggi adalah kemampuan mendengarkan dengan nilai 84,90 yang terletak pada kategori baik.

Selanjutnya peneliti menganalisis seluruh data observasi setiap subjek untuk memperoleh nilai rata-rata kemampuan komunikasi matematis mahasiswa selama pembelajaran yang disajikan pada tabel distribusi frekuensi berikut ini.

Tabel 10. Nilai Akhir Kemampuan Komunikasi Matematis Mahasiswa Melalui Pembelajaran Berbantuan Maple

\begin{tabular}{|c|c|c|c|}
\hline Nilai & Kategori & Frekuensi $(\boldsymbol{f})$ & Persentase \\
\hline $86-100$ & Sangat Baik & 7 & 18 \\
\hline $71-85$ & Baik & 24 & 62 \\
\hline $56-70$ & Cukup & 5 & 13 \\
\hline $41-55$ & Kurang & 3 & 8 \\
\hline $0-40$ & Sangat Kurang & 39 & 0 \\
\hline \multicolumn{2}{|c|}{ Jumlah } & \multicolumn{2}{|c}{} \\
\hline Nilai Rata-Rata
\end{tabular}

Dari perhitungan di atas maka dapat dikatakan bahwa kemampuan komunikasi matematis mahasiswa memiliki nilai rata-rata sebesar 76,46. Hal ini menunjukkan bahwa nilai rata-rata kemampuan komunikasi mahasiswa berkategori baik.

\section{KESIMPULAN}

Berdasarkan hasil penelitian diperoleh kesimpulan bahwa peningkatan kemampuan komunikasi matematis mahasiswa yang mendapat PBM lebih baik daripada mahasiswa yang mendapat pembelajaran konvensional. Adapun saran peneliti terkait 
dengan hasil penelitian yaitu dosen dapat menerapkan pembelajaran Kalkulus Integral berbasis Maple dalam upaya untuk meningkatkan kemampuan komunikasi matematis mahasiswa.

\section{DAFTAR PUSTAKA}

Barrody, A, J. (1993). Problem Solving, Reasoning, and Communicating, (K-8): Helping Children Think Mathematically. New York: Merill as imprint of Macmillan Publishing Company.

Depdiknas (2006). Kurikulum 2006 Standar Kompetensi Mata Pelajaran Matematika Sekolah Menengah Atas (SMA) dan Madrasah Aliyah (MA). Jakarta: Depdiknas.

Hardianto, D. (2012). Pemanfaatan Software Komputer untuk Meningkatkan Kecerdasan Emosi (EQ) Anak. [online]. Tersedia: http://staff.uny.ac.id/sites/default/files/penelitian/Deni

Hardianto,M.Pd./Pemanfaatan Software Komputer Untuk Meningkatkan Kecerdasan Emosi.pdf.

Ibrahim, N. (2009). Pengaruh Pembelajaran Berbantuan Komputer Terhadap Hasil Belajar (Meta Analisis). Jurnal Pendidikan dan Kebudayaan. 15, (1), 108-125.

Iskandar A., Burhan. (2012). Peningkatan Kemampuan Pemahaman dan Komunikasi Matematis Siswa SD Melalui Pendekatan Realistic Mathematics Education (RME). [online]. Tersedia: http://eprints.uny.ac.id/7511/1/P\%20-\%2016.pdf.

Kartono. 2005. Aljabar Linier, Vektor, dan Eksplorasinya dengan Maple. Yogyakarta: Graha Ilmu.

Lim, L \& Pugalee, D.K. (2005). Using Journal Writing to Explore "They Communicate to Learn Mathematics and They Learn to Communicate Mathematically" [Online]

Lindquist, M.M. \& Elliot, P.S. (1996). Communication an imperactive for Change: A Conversation with Mary Lindquist. Communication in Mathematics K-12 and Beyond. Virginia: NCTM.

National Council of Teachers of Mathematics. (2000). Prinsiples and Standards for School Mathematics. Reston: NCTM.

Paradesa, R., Zulkardi, \& Darmawijoyo. 2010. Bahan Ajar Kalkulus II Menggunakan Macromedia Flash dan Maple di STKIP PGRI Lubuk Linggau. Jurnal Pendidikan Matematika, 4(1), 96-109.

Polla, G. (1999). Effort to increase Mathematics for All Through Communication Responses to a Performances Learning. [Online] 
Stacey, K. (2005). The Place of Problem Solving in Contemporary Mathematics Curriculum Document. Journal of Matehmatics Behaviour, 23,341-350.

Wijaya, A. \&Surya S.P. (2009). Pemanfaatan Komputer Sebagai Media Pembelajaran Matematika di SMP. Yogyakarta: P4TK Matematika. 